\title{
Accreditation of general practices: challenges and lessons
}

\section{S A Buetow, J Wellingham}

Qual Saf Health Care 2003;12:129-135

To flourish, practice accreditation must meet challenges. It needs to manage uncertainty over its effectiveness and cost effectiveness, to address concerns that it erodes professional autonomy, and to promote and elucidate the conditions under which it is appropriate. Lessons from Australia and New Zealand help to focus these challenges. The lessons include the need to reward quality practices, loosen professional control over accreditation, trade some consistency of standards for validity, develop standards that acknowledge cultural diversity, and be transparent. Another lesson is to separate quality control from quality improvement within a coordinated systems based framework, with practices being helped to pay for accreditation and quality improvement. Such assistance is important because, in the presence of unintended variations in practice service delivery, all practices should have to show that they meet or exceed minimum standards while aiming for excellence.

See end of article for authors' affiliations

Correspondence to: Dr S A Buetow, Department of General Practice and Primary Care, School of Medicine, University of Auckland, Private Bag 92019, Auckland, New Zealand;

s.buetow@auckland.ac.nz

Accepted for publication 28 December 2002
D on't hold your breath. Internationally, an increasing number of practice accreditation programmes are being developed or are in use to protect and enhance quality and safety in primary health care (box 1). ${ }^{1-9}$ However, in most health systems practice accreditation has yet to become widely accepted by general practitioners (GPs). Even in Australia where the concept is a decade old ${ }^{10}$ it continues to be controversial. ${ }^{11}$ Concerns persist despite two developments. One is the long history of accreditation of training practices and hospitals in countries such as Australia, the UK and New Zealand ${ }^{10-13}$; the other is international acceptance of the need for independent recognition of vocational training for general practice and (re)approval of the credentials of individual health professionals. ${ }^{10}{ }^{11}$

There are several barriers to GP acceptance of practice accreditation. Compared with hospital environments which have a long history of accreditation, general practices have been considered more difficult and less important to accredit. $^{314}{ }^{15}$ Practice accreditation can be expensive for practices and is still poorly understood. ${ }^{3}$ With exceptions, it has been little researched. ${ }^{14}{ }^{15}$ For practice accreditation to develop, gain widespread approval, and be of both relevance and benefit to patients, the challenges facing it must be made clear.
This paper aims to offer a personal response to four questions:

(1) What is practice accreditation?

(2) What is it meant to achieve?

(3) What challenges does it face?

(4) What can be learnt?

The response to the first three questions, in particular, draws on a non-systematic review of relevant research literature in English. This literature was identified from personal files, electronic databases, the Internet, reference lists of retrieved works, and conversations with colleagues. By comparison, discussion around the fourth question introduces a more personal view which focuses on lessons from Australian and New Zealand experience. This experience includes our own involvement with the 2001 Royal New Zealand College of General Practitioners (RNZCGP) trial of practice accreditation standards. Helping to crystallise the challenges facing practice accreditation, the lessons identified have international relevance to an evolving field in which not altogether dissimilar health systems may learn much from each other. ${ }^{16}$ The paper is further intended to inform and stimulate debate occasioned by the views of others.

Box 1 Examples of national programmes for practice accreditation

United Kingdom

- Royal College of General Practitioners' (RCGP) team based practice accreditation programme $^{12}$

- King's Fund health quality service programme for primary healthcare teams ${ }^{3}$

- Northumberland local accreditation programme $^{4}$

Australia

- Royal Australian College of General Practitioners (RACGP) entry standards for general practice $^{5}$

New Zealand

- Royal New Zealand College of General Practitioners (RNZCGP) practice accreditation standards ${ }^{6}$

- Te Wana quality programme

United States

- American Medical Association 8

- Joint Commission on the Accreditation of Healthcare Organizations (JCAHO) ${ }^{9}$ 
Box 2 Concepts with which voluntary accreditation may be confused

- Certification: a process by which an individual or healthcare organisation is recognised by an authorised agency as meeting predetermined requirements, beyond those set for licensure or met by similar individuals or organisations

- Credentialling: a process used to assign specific clinical responsibilities to health professionals within a healthcare organisation

- Inspection: an official examination of a professional or healthcare organisation

- Institutional accreditation: a process that healthcare organisations may need to undergo to avoid sanctions or receive public money; almost a synonym for authorisation

- Licensure: a mandatory and regulated process that, by written testament of ability to meet minimum standards of health care and safety, legally authorises a professional or healthcare organisations to operate

- Vocational registration: a process and outcome of peer review of the ability of individuals to provide specified services independently

\section{WHAT IS PRACTICE ACCREDITATION?}

Accreditation gives official approval or endorsement. ${ }^{17}$ In general practice it typically applies to GPs' work settings (practices or clinics) in recognition of delivery of general practice services, and to accreditation agencies in recognition of competency to accredit general practices. ${ }^{12}$ It currently describes a voluntary but formal process of self-assessment and external and independent peer review. All services in a practice (traditional accreditation) or specific selected services (focused accreditation) may be accredited. ${ }^{18}$ Accreditation reviews assess "measurable" performance, or capacity to perform, against predetermined and explicit standards that GPs and other stakeholders have produced. Results may include recommendations for continuous improvement of safety and quality in the practice. The accreditation process assumes that the structure and operation of practices significantly influence outcomes for patients ${ }^{19}$ (and costs, quality and value ${ }^{20}$ ), but recent efforts have been made to adopt outcomes measures-for example in the United States. ${ }^{20}$

Practice accreditation typically combines weak social control, through a process of external review, with elements of self-regulation through internal assessment and self-directed but professionally supported performance improvements. ${ }^{21}$ In the former context, accreditation is part of a network of activities for quality control with which it is related but should not be confused (box 2). Complementary approaches to the development and external assessment of practice quality are external peer review of professional performance, the Excellence model, and the International Organization for Standardization model (table 1). ${ }^{12}$ As with accreditation, they involve assessments against standards.

However, the term "standards" can have different meanings, reflecting in part the purposes and context of the accreditation system in particular settings. Standards refer first to predetermined qualities required or expected of practices. These qualities can vary by level, content, derivation, and measurability. ${ }^{22}$ Standards may also vary in explicitness. In Australia, for example, practice standards are stated explicitly, with specific criteria prescribing how standards are to be met. By contrast, essential criteria such as "nominated staff are responsible for recall and screening ${ }^{\prime \prime}$ define accreditation standards for New Zealand general practice. Secondly, empirical standards describe qualities that practices have achieved. These standards can refer to performance rates ${ }^{23}$ within or between practices, such as the percentage of practices that comply with a particular criterion. ${ }^{2}$

\section{WHAT IS PRACTICE ACCREDITATION MEANT TO ACHIEVE?}

Practice accreditation can have at least five purposes: (1) quality control; (2) regulation; (3) quality improvement; (4) information giving; and (5) marketing.

\section{Quality control}

This purpose protects public safety and meets demands for increased openness and accountability to the public (patients and taxpayers), ${ }^{21}$ government and other stakeholder groups. Quality control seeks to "assure or, even better, improve the trust of external parties such as patients, financiers and

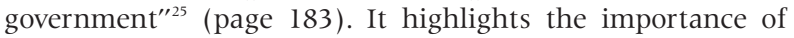
medicine as a profession and service. It also reflects the need to eliminate unnecessary and inappropriate interventions, increase equity of access, ${ }^{26}{ }^{27}$ monitor health outcomes, and demonstrate that practices function efficiently, offering value for money.

\section{Regulation}

This aids quality control but differs from it in ways benefiting practices. In Australia, for example, compliance by practices

Table 1 Approaches to external quality assessment in general practice

\begin{tabular}{|c|c|c|c|c|}
\hline & Aim & Rationale & Method & Outcomes \\
\hline $\begin{array}{l}\text { Peer review of } \\
\text { professional } \\
\text { performance }\end{array}$ & $\begin{array}{l}\text { Assess professional } \\
\text { performance of } \\
\text { individuals and/or } \\
\text { practice team }\end{array}$ & $\begin{array}{l}\text { Professionals can } \\
\text { self-regulate to } \\
\text { improve } \\
\text { professional } \\
\text { performance }\end{array}$ & $\begin{array}{l}\text { Systematic site visit } \\
\text { and peer review }\end{array}$ & $\begin{array}{l}\text { Assessment report. } \\
\text { No certificate of } \\
\text { achievement }\end{array}$ \\
\hline Practice accreditation & $\begin{array}{l}\text { Assess organisation } \\
\text { and delivery of } \\
\text { specific practice } \\
\text { services }\end{array}$ & $\begin{array}{l}\text { Practices need to } \\
\text { demonstrate public } \\
\text { accountability }\end{array}$ & $\begin{array}{l}\text { Peer assessment } \\
\text { against explicit } \\
\text { standards }\end{array}$ & $\begin{array}{l}\text { Accreditation of } \\
\text { practice and } \\
\text { development of } \\
\text { systems necessary } \\
\text { for quality } \\
\text { improvement }\end{array}$ \\
\hline Excellence model & $\begin{array}{l}\text { Promote total quality } \\
\text { management }\end{array}$ & $\begin{array}{l}\text { Quality } \\
\text { improvements and } \\
\text { excellence can be } \\
\text { achieved through } \\
\text { quality management }\end{array}$ & $\begin{array}{l}\text { Framework for } \\
\text { self-assessment and } \\
\text { award schemes }\end{array}$ & $\begin{array}{l}\text { Systematic quality } \\
\text { improvement and } \\
\text { quality awards }\end{array}$ \\
\hline $\begin{array}{l}\text { International } \\
\text { Organization for } \\
\text { Standardization (ISO) } \\
\text { model }\end{array}$ & $\begin{array}{l}\text { Implement } \\
\text { international norms } \\
\text { for quality systems }\end{array}$ & $\begin{array}{l}\text { Quality systems and } \\
\text { management } \\
\text { processes can be } \\
\text { strengthened and } \\
\text { standardised to } \\
\text { achieve efficiencies }\end{array}$ & $\begin{array}{l}\text { Audit by ISO } \\
\text { experts, not peers, } \\
\text { against generic, } \\
\text { international } \\
\text { standards }\end{array}$ & $\begin{array}{l}\text { Certificate of } \\
\text { compliance with } \\
\text { standards, not } \\
\text { intended for } \\
\text { organisational } \\
\text { development }\end{array}$ \\
\hline
\end{tabular}




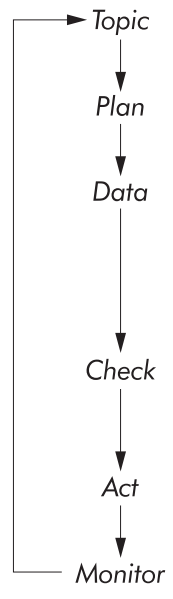

Practice decides to undertake a practice assessment

Assessing agency and other stakeholder groups identify standards of care

Audit data are collected from the practice: (a) Self-assessment by the practice team (b) Subsequent one-day site visit by a pair of external peers (a GP with either a practice nurse or practice manager) to review the practice

With the whole practice team, assessors discuss the findings and develop an action plan; the practice also receives a written report

Practice team uses assessment findings to develop strategies for practice improvements

Practice team plans review date to assess changes and progress

Figure 1 RNZCGP quality cycle for practice assessments.

with legal, safety, ${ }^{28-30}$ and other essential requirements for accreditation defines a gateway to additional funding. ${ }^{31}$ Moreover, regulatory or quasi-regulatory functions of practice accreditation may go beyond quality control. In the US, for example, the Joint Commission on the Accreditation of Healthcare Organizations (JCAHO) - which evaluates ambulatory care facilities, including group practices and student health care centres, among other organisations-emphasises maximum achievable standards. ${ }^{9}$ Yet, the JCAHO is a quasi-public regulatory body, despite its descriptive policy, whose evaluations for performance improvement often fulfil state licensing requirements and may meet certain Medicare certification requirements. ${ }^{9}$

\section{Quality improvement}

Accreditation of practices enables their entry into or development of elements of a framework of continuous quality improvement (CQI). According to this framework, the whole practice team can improve over time the quality of the organisation and delivery of its services. Accreditation systems for healthcare organisations have tended to redefine CQI in their own terms, ${ }^{32}$ de-emphasising the use of systematic methods and statistical tools for process improvements. Nevertheless, scope to improve practice quality and safety can be identified by comparing individual practices against accreditation standards, measures of their own past performance, and/or rates or norms based on accreditation results from other practices (benchmarking). Opportunities for feedback and support encourage practices to apply for accreditation, despite frequently mixed responses to systems of external review. ${ }^{33}$ These opportunities include education, clarification of work roles, and practical assistance. Such benefits can be attractive in general practice where isolation is common, ${ }^{16}$ practices are often widely dispersed, and GPs may work single handed, especially in countries such as the Netherlands, France and Germany. In countries such as New Zealand the non-blame focus of CQI and the involvement of practices at every stage of practice assessments (fig 1) have also helped recruitment. ${ }^{6}$ These assessments enable practices to make and plan developmental changes that meet the demands of developing quality and clinical governance agendas. ${ }^{19}$ The changes can benefit patients and all practice staff $^{11}$ - for example, by improving practice services and helping to address problems with morale, recruitment, and retention. ${ }^{34} 35$

\section{Information giving}

Practice accreditation seeks to offer an agreed and credible measure of the quality and safety of individual practices. ${ }^{9}$ Stakeholders in general practice care can use this measure to support comparisons between practices, show levels of adherence to standards, highlight opportunities for improvement, inform and guide decision making, and enhance confidence. Information made available by practice accreditation may also change behaviour by individuals, practices and the health system, as demonstrated by the use and public disclosure of performance indicators and other comparative performance data. ${ }^{36}$

\section{Marketing}

In a competitive health care environment ${ }^{33}$ accreditation can have a marketing benefit for accredited practices until they account for a high proportion of all practices. ${ }^{37}$ In the US, health maintenance organizations "that are accredited make much of the fact in their marketing" ${ }^{\prime 38}$ (page II-6). A marketing benefit may put competitive pressure on practices to gain accreditation and develop programmes for quality improvement ${ }^{39}$ However, rural, isolated and small practices, among others, may resent this pressure.

\section{WHAT CHALLENGES DOES PRACTICE ACCREDITATION FACE?}

The practice accreditation process faces at least three sets of challenges to its acceptability, implementation, and usefulness: (1) to manage uncertainty over its effectiveness and cost effectiveness; (2) to manage concerns about erosion of professional autonomy; and (3) to elucidate and promote the conditions under which practice accreditation is appropriate.

\section{Demonstrate effectiveness and cost effectiveness}

Effectiveness here means the ability of practice accreditation programmes to achieve their purposes. Five sets of factors challenge the effectiveness and cost effectiveness of programmes. Focusing on quality assurance as a mechanism for both quality control and regulation, and on CQI, they describe the context in which it is necessary to demonstrate to all the stakeholder groups that accreditation is effective and cost effective.

\section{Quality improvement has unknown effectiveness}

The organisation-wide benefits of CQI as a method for improving outcomes and lowering costs have not been consistently demonstrated in healthcare organisations, ${ }^{39} 40$ especially within general practice. ${ }^{41}$

\section{Quality assurance is a misnomer}

Quality and mutual trust cannot be ensured. They can usually be protected and, at least in the short term, enhanced-but not made sure or certain..$^{42}$ One reason for this is that health systems lack "expertise in identifying organisations which are liable to have serious problems before they occur and preventing them" ${ }^{\prime 43}$ (page S40). A second reason is the uncertain impact of external assessments, including practice accreditation, on practice performance and clinical outcomes. ${ }^{22}$ It is not clear that practice accreditation offers an effective way to control or improve quality. Especially in general practice, where much illness is undifferentiated and self-limiting, relationships between organisational structures, processes, and outcomes are poorly understood. ${ }^{44}$ In part, this reflects difficulties in measuring practice performance, interpreting results, and determining appropriate actions to take in the light of these results.

Quality assurance discourages improvements to quality The minimum standards required by quality assurance are unlikely to challenge many practices and stimulate performance improvements. ${ }^{15}$ Worse, the threat of deferring accreditation or of more severe consequences can create an environment of fear in practices. ${ }^{45}$ Such an environment may be expected to stifle performance ${ }^{46}$ and the development of quality initiatives ${ }^{20}$ such as "unified multiprofessional educational 
strategies". ${ }^{35}$ Practices are encouraged defensively to accept minimum standards for accreditation (which may be for services that can be quantified) rather than excellence ${ }^{47}$ and what is in the best interests of patients ${ }^{46}$ (page 47).

\section{Assurance and improvement of quality have conflicting philosophies}

Quality assurance seeks the certainty indicated by compliance with minimum standards. ${ }^{20}$ Non-complying practices are assumed to have poor intentions and are "weeded out". Accreditation of such practices withholds public accountability for their services. It weakens the credibility of and public confidence in standards and accreditation programmes. However, not to accredit practices continuing to perform below minimum standards connotes blame. This is anathema to CQI, which is non-punitive, considers the quality of practice services to be in a continual state of evolution, and values long term relationships based on respect. Recognising that measurement and reporting alone cannot control or improve quality, CQI focuses on opportunities to do things better, rather than on detecting problems. A key question therefore is how can accreditation protect the public from poor management but promote blame-free quality improvement (as in New Zealand $^{6}$ and the $\left.\mathrm{UK}^{2}\right)$ ? The nature and implications of this tension have yet to be widely acknowledged.

\section{Practice accreditation is costly}

Practices face a challenge to their willingness to tolerate uncertainty over whether the uncertain benefits of accreditation programmes outweigh what can be significant costs (monetary, time, effort, and other staff costs) to themselves. These costs are associated with preparing for and participating in the assessment-and managing consequent change. A further challenge is to evaluate the cost effectiveness of establishing and running an agency to accredit practices. Accreditation programmes are often managed by not-forprofit organisations ${ }^{25}$ that depend on volunteers to develop standards without payment and on assessors to give up work time to assess practices for little or no fee. ${ }^{22}$

\section{Manage threats to professional autonomy}

Practice accreditation must manage concern that it threatens GPs' own professional autonomy and that of general practice. Six conditions underpin this challenge. (1) A potential tension between a desire for practice accreditation through selfregulation by the profession and the imperative to increase the public accountability of practices through non-partisan performance evaluation and monitoring. (2) Through quality assurance processes that externally set and review compliance with accreditation standards, GPs face diminution of their organisational control at the practice level which they have sustained largely through clinical audit and strong professional values. (3) Practice accreditation enables other stakeholders (such as funders, practice nurses, practice managers, and consumer representatives ${ }^{48}$ ) to prosecute their own agendas in pursuit of a collective good. (4) The voluntary status of practice accreditation will become a misnomer as a growing proportion of all practices embraces the concept, and as recognition grows that it is incongruous that, in the face of variations in service delivery, practices can choose not to be assessed against essential standards. (5) GPs sometimes express concern that rigid accreditation standards ${ }^{46}$ and standards prescribed for all practices will restrict their autonomy and flexibility ${ }^{19}$ and not reflect and support the diversity inherent to general practice. Practices must be able to provide services that are responsive to the particular needs of their own patients and, arguably, practices should not be required to meet standards at least partly outside their own control-for example, patient satisfaction may be only partially controllable by individual practices. ${ }^{49}$ (6) The
Box 3 Factors promoting GP support for practice accreditation

- Practices face media and public pressure for accountability and competitive pressure as a stimulus for quality improvement.

- Accreditation is generally assumed to be in the public good, despite the dearth of research evidence.

- By improving organisational quality, practice accreditation is expected to facilitate the clinical ability of GPs to deliver practice services.

- Accreditation requires GPs to influence how much control they themselves can have over the development and application of practice standards.

- GPs see themselves as integral to, rather than independent from, their practices.

- Practice accreditation represents control not by managers but rather a cooperative constituency of stakeholders, operating by consensus.

- Practice accreditation may confer a marketing advantage where, as in Australia and New Zealand, patients have significant choice over which practice(s) to attend and accreditation results can be made known to patients.

confidentiality of the information that GPs and other practice staff share with assessors is likely to be "tempered over time by the government's, purchaser's, and public desire to have more detailed information about an organisation's performance $^{\prime 50}$ (page 257) and by the responsibility of the accreditation agency to "weed out bad apples". Nevertheless, for the reasons listed in box 3, most GPs are likely to relinquish their authority to operate their practices as they wish and will support practice accreditation if they see it as affordable and cost effective.

\section{Demonstrate appropriateness}

The appropriateness of any accreditation programme is central to its usefulness and acceptability. A key challenge therefore is to promote and elucidate the conditions under which practice accreditation is appropriate. Four such conditions are identified.

(1) The extent to which programmes for practice accreditation are consistent with their stated purposes. ${ }^{22}$

(2) The individual programmes-including accreditation standards, practice assessors, assessment methods and the reporting and use of results-should be subject to independent scrutiny and meet explicit criteria. ${ }^{12}$ Thus, for example, there is a need for improved training of external assessors in countries including New Zealand ${ }^{6}$ and the UK. ${ }^{51-53}$ Moreover, practice accreditation programmes should demonstrate predictive validity because of the uncertain relation between practice structure (the core of most accreditation) and both process and outcome. ${ }^{64}$ They should also seek to maximise the representativeness of practices in trials to validate accreditation as a voluntary activity. Meeting the last challenge would minimise the bias inherent in practice self-selection.

(3) Acknowledgement of-and steps to resolve-the tension between, on the one hand, the need for comprehensive standards and a process permitting full review in individual practices and, on the other, constraints on practice resources such as time, effort, and money. ${ }^{61-53}$

(4) There is a need to incorporate the perspective of each key stakeholder group and so promote a sense of shared ownership of, and commitment to, the accreditation programme.

\section{WHAT CAN BE LEARNT?}

Lessons from programmes for practice accreditation in Australia and New Zealand illustrate a response to, and elaborate on, the foregoing challenges. In Australia, practice accreditation was first canvassed as a concept in $1991^{10}{ }^{11}$ and 
then implemented in 1998 as a voluntary, educational, and supportive process. In New Zealand practice accreditation is imminent. The RNZCGP completed a trial in 2001 of essential and desirable standards for practice accreditation and a process to apply them. Involving a national sample of 74 volunteer practices, it found that the process used (fig 1) was acceptable to practices and assessors. The standards had high face validity, content validity, and construct validity, and fair internal consistency. ${ }^{6}$ They were subsequently revised, with the standards considered essential by the RNZCGP distinguished from those required by legislation. ${ }^{55}$ Six particular lessons from the Australian and New Zealand experiences are discussed.

\section{Reward quality practices}

To help practice accreditation become effective, Australia introduced a Practice Incentives Program (PIP) in July 1998. This program offers financial incentives to practices with formal accreditation or working towards accreditation. ${ }^{31}$ Accreditation does not attract funding but rather is a gateway to payments for activities or services (such as information management and information technology, after hours care, and student teaching) that might not otherwise be remunerated. Underlying the programme was a desire of the Australian government to fund high quality health care rather than throughput (numbers of patient consultations). ${ }^{11}$ Another benefit of the programme is to lower the cost to practices of participation in an accreditation programme. Uptake of PIP by practices has grown rapidly.

In New Zealand, funding incentives similar to the PIP for practice accreditation are under negotiation with the government. They are likely to be funded through district health boards which were elected in 2001 to be responsible for the provision and eventual public funding of most health and disability services for local populations.

\section{Loosen professional control}

In Australia, practices can seek accreditation through Australian General Practice Accreditation Limited (AGPAL) or General Practice Australia (GPA) Accreditation Plus. Both are independent of the government. However, AGPAL operates as an "independent" arm of the Royal Australian College of General Practitioners (RACGP) and it is unclear whether accreditation "owned and controlled by the profession for the profession" ${ }^{156}$ can be truly non-partisan. AGPAL dominates the Australian market for practice accreditation, yet most GPs could be expected to participate in a programme for practice accreditation even if the profession did not control it (box 3). It is therefore difficult to justify the current role for AGPAL, although it gives GPs a choice in accreditation. Since the benefits of accreditation do not depend on professional control, we believe that the profession in Australia, as elsewhere, should manage the challenge to its own autonomy by sharing control with other stakeholder groups, including patients. GPs could still influence the accreditation process - for example, by contributing to the development of standards and the assessment of practices.

The RNZCGP has not learnt from the Australian experience that practice accreditation should be independent of general practice as a profession. The RNZCGP will retain control of practice accreditation standards in New Zealand, and has agreed to license AGPAL to set up QIP-NZ to operate a practice accreditation programme. An advisory group to QIP-NZ, representative of the key stakeholder groups, will provide support, guidance and information about professional issues and trends in the New Zealand health sector. This advisory group will distance QIP-NZ from the RNZCGP and help to ensure accountability.

Trade some consistency of standards for validity

Practice accreditation by AGPAL or GPA Accreditation Plus indicates compliance with the 1996 RACGP entry standards for general practice. These were field tested in 1994 by the RACGP $^{57}$ and in more detail by a consortium of GP researchers. ${ }^{58}$ Results from both investigations indicated that the standards and assessment process were acceptable to participating GPs. However, were the standards and process appropriate? Only the more objective standards recorded acceptable inter-assessor reliability, ${ }^{58}$ and concordance was poor between methods of assessment that were more objective (for example, medical record review) compared with those that were less objective (for example, GP interview). ${ }^{58}$ To increase the consistency of assessments it has therefore been concluded by others that "when the main objective of a visit is accreditation, objective scoring is crucial" ${ }^{\prime 59}$ (page 53).

Yet so-called objective assessments offer only partial measures of overall practice performance and are not without their own biases (of selection and measurement). So, is the lesson to increase "objectivity" and hence reliability? We believe it is not. Less objective standards would give up some consistency but would help to document aspects of quality that are not easily measured and temper consistency of application with flexibility. A balance is thus needed between more and less objective standards and evidence of compliance. ${ }^{58}$

\section{Be transparent}

Lack of transparency regarding control by the profession was noted above. A related issue is that, in New Zealand, many practice assessors and practices themselves appeared not to understand that the purpose of the RNZCGP trial was to validate the practice accreditation standards and assessment process. Our impression is that practice participation in the trial most commonly reflected a desire to undergo a process of peer review and receive feedback in the absence of fully understanding that the validity of each was still untested.

Also, the New Zealand trial did not acknowledge the tension between CQI and quality assurance as distinct purposes of practice accreditation. Indeed, the RNZCGP still asserts that "measurement alone [for quality assurance] is not useful and the synergy occurs when it is associated with a Continuous Quality Improvement approach" ${ }^{\prime 55}$ (page 5). As a consequence, lessons for the appropriateness of practice accreditation programmes include the need to tell potential participants clearly from the outset which type of accreditation is being used, for what purpose(s), and with what benefits and risks to themselves.

\section{Separate quality assurance from CQI}

As an external mechanism, assessments for accreditation may stimulate improvements to quality from within practices. Under proposed arrangements in New Zealand, the feedback session with each practice team will enable assessors to promote CQI. However, as indicated above, the RNZCGP has not described how the assessors can advocate the nonpunitive philosophy of CQI yet later withhold accreditation of individual practices. Accordingly, we believe that quality assurance and CQI require separation-albeit within a coordinated systems based framework in order to avoid complete fragmentation.

To these ends, the RNZCGP has at least stated that the new agency for practice accreditation (QIP-NZ) will not be responsible for CQI in practices after or between practice assessments. Practices themselves will have this responsibility, most likely with funding support from district health boards. Meanwhile, independent practitioner associations (groupings of GPs in structures such as registered companies, trusts and incorporated societies) will make personnel available to help practices improve their quality of care. The RNZCGP will continue to offer leadership and guidance to its members.

\section{Acknowledge cultural diversity}

RNZCGP standards for practice accreditation appropriately acknowledge and celebrate cultural diversity in the New Zealand population. They require practices to be aware of and 
Box 4 Additional lessons from the RNZCGP practice standards validation trial

- Require assessors to become familiar with different record review systems before the assessment

- Develop an assessor guide to aid the interpretation of standards

- Provide ongoing training for assessors

- Provide clear instructions to practices about the selfassessment

- Require all practices to complete a self-assessment form in preparation for the assessment visit

- Ensure financial and systems support for practices to participate and succeed, especially where they have not met legal and safety standards

- Find a way to overcome practice concerns about the cost of participating in future assessment processes without funding

- Use the feedback session with each practice team to identify opportunities for improvement, brainstorm and critically appraise options, and set in train a process and timeline for moving forward to a set review date

- Obtain from the outset a commitment from the whole practice team to attend the feedback session and participate in shared processes for quality improvement

responsive to cultural needs, in particular those affecting the indigenous Maori population. Practices are expected, for example, to meet bi-cultural obligations under New Zealand's founding document, the Treaty of Waitangi. This recognition of cultural diversity contrasts directly with the RACGP entry standards ${ }^{5}$ and RCGP standards for accreditation. ${ }^{1}$ In addition, an advisory committee to QIP-NZ will include representation from the new Maori Faculty of the RNZCGP. Box 4 summarises other lessons learnt from the RNZCGP trial.

\section{CONCLUSIONS}

This paper has considered challenges facing practice accreditation and some lessons from Australian and New Zealand experiences that help to crystallise the challenges. The paper poses more questions than it answers, but raises awareness of some of the main difficulties and opportunities associated with establishing and operating programmes for practice accreditation. It seeks to stimulate debate on issues including how best to foster effective and appropriate accreditation programmes acceptable to the key stakeholder groups.

One lesson, which reinforces UK experience, ${ }^{35}$ is the need still to acknowledge the tension between quality assurance and CQI as purposes of accreditation. It is necessary, in our opinion, to separate these roles, with different organisations overseeing their implementation. CQI should be managed internally by practices and general practice as a profession, while quality assurance requires external assessments for the purpose of practice accreditation. Yet, this begs the questions of who would be responsible for each process? How can lack of coordination be avoided? And can practices, as small and relatively low income businesses, afford two separate processes?

To avoid a complete disjunction of CQI from quality assurance, countries such as New Zealand and the UK need to coordinate both processes within their systems based frameworks of clinical governance. These frameworks have been designed to support relationships, set clear lines of responsibility and accountability, and minimise duplication and confusion. They have a particular need to ensure financial support for practices that commit to quality initiatives like accreditation, as happens in Australia.

Clinical governance requires effective leadership by the profession. To manage the threat that practice accreditation poses to professional autonomy, the profession should, we believe, share its control of accreditation with other stakeholder groups. Neither the UK-with its fragmented systems for

\section{Key messages}

- Practice accreditation has yet to be widely established in most health systems; concerns persist despite mounting international recognition of its importance.

- The purposes of practice accreditation can include quality control, regulation, quality improvement, information giving, and marketing.

- Challenges include the need for accreditation to demonstrate effectiveness, cost effectiveness and appropriateness and to manage professional concern with losing autonomy.

- Lessons include the need to reward quality practices, loosen professional control, trade some consistency of standards for validity, acknowledge cultural diversity in the standards, and separate quality control from quality improvement within a systems based framework.

- Practices need help to pay for accreditation and quality improvement.

- Accreditation will not benefit patients unless it is accountable, contributes to improved quality of care, and patients have access to information about which practices are accredited.

practice accreditation-nor New Zealand has learnt this lesson from the Australian experience. Yet it is critical for patients.

Patients require practice accreditation to be independent, to be developed with them through consultation at each stage in the context of other structures and processes that support patients, and to be open to public scrutiny. ${ }^{48}$ To be relevant and acceptable to patients, practice accreditation must also protect quality and safety in health care, offering patients visible and immediate access to information about which practices are accredited. ${ }^{48}$ Any failure to deliver on these requirements would weaken general practice care for patients by tying up scarce resources that might otherwise be better used.

With support, all practices should be required to demonstrate their ability, or capability, to meet at least minimum standards whilst aiming for excellence. The voluntary nature of practice accreditation will then become a misnomer as increasing numbers of practices seek it. Only if practice accreditation cannot meet the challenges and develop should practices and patients, among others, oppose it. We expect that practice accreditation will succeed, achieving its explicit and specific purposes for the benefit of all groups including, most importantly, the end users of practice services-patients.

Authors' affiliations

S A Buetow, J Wellingham, Department of General Practice and Primary Care, School of Medicine, University of Auckland, Auckland, New Zealand

\section{REFERENCES}

1 Royal College of General Practitioners. RCGP standards and criteria for accreditation. In: Walshe K, Walsh N, Schofield T, et al, eds. Accreditation in primary care: towards clinical governance. Oxford: Radcliffe Medical Press, 2000: 127-47.

2 Schofield T, Blakeway-Phillips C. The RCGP primary healthcare team-based accreditation programme. In: Walshe K, Walsh N, Schofield $\mathrm{T}$, et al, eds. Accreditation in primary care: towards clinical governance. Oxford: Radcliffe Medical Press, 2000: 45-55.

3 Corbett-Nolan A. The King's Fund health quality service. In: Walshe K, Walsh N, Schofield T, et al, eds. Accreditation in primary care: towards clinical governance. Oxford: Radcliffe Medical Press, 2000: 31-44.

4 Foreman A, Mifford P. Practice accreditation: the Northumberland approach. In: Walshe K, Walsh N, Schofield T, et al, eds. Accreditation in primary care: towards clinical governance. Oxford: Radcliffe Medical Press, 2000: 57-69.

5 Royal Australian College of General Practitioners (RACGP). 1996 entry standards for general practice. Sydney: RACGP, 1996.

6 Gillon M, Buetow S, Talboys S, et al. Aiming for excellence. The RNZCGP practice standards validation field trial final report. Wellington: RNZCGP, 2001.

7 Roseveare C. Te Wana quality programme: an evaluation of the pilot. Master of Public Health Thesis. Dunedin: University of Otago, 2002. 
8 American Medical Association. American medical accreditation program, standards and criteria. Chicago, IL: American Medical Association, 1997.

9 Joint Commission on Accreditation of Health Organizations (JCAHO). Welcome to the Joint Commission homepage. Oakbrook Terrace, IL: JCAHO, 2002

10 Howe B. Health care in Australia-directions for reform in the 1991-92 budget. Budget related paper no. 9. Canberra: Australian Government Publishing Service, 1991.

11 Bollen M. Recent changes in Australian General Practice. Med J Aust 1996;164:212-5

12 Shaw C. External quality mechanisms for health care: summary of the ExPeRT project on visitatie, accreditation, EFQM and ISO assessment in European Union countries. Int J Qual Health Care 2000;12:169-75.

13 Donaldson B. Accreditation for health care organisations. Health Manager 1997;6:10-23.

14 Scrivens E. Widening the scope of accreditation: issues and challenges in community and primary care. Int J Qual Health Care 1998;10:191-7.

15 Walshe K, Walsh N. Accreditation in primary care. In: Walshe K, Walsh N, Schofield T, et al, editors. Accreditation in primary care: towards clinical governance. Oxford: Radcliffe Medical Press, 2000: $1-15$.

16 Baker R. Quality improvement in primary health care: a European perspective. Qual Health Care 1998;7:1-4.

17 Merriam-Webster Inc. Merriam-Webster's collegiate dictionary. 19th edition: Franklin Electronic Publishers, 2001. http://www.m-w.com/ netdict.htm

18 Silimperi D. Focused accreditation. Q A Brief 1999;8:25-30.

19 Bollen M, Miller G, O'Halloran D. Accreditation of general practices: medical perspectives. In: Douglas R, Saltman D, eds. Everyone's watching: accreditation of general practice. NCEPH discussion paper no. 7. Canberra: NCEPH, 1992

20 Scrivens E. Accreditation: protecting the professional or the consumer? Buckingham: Open University Press, 1995.

21 Nichols A, Schilit R. Accreditation of human service agencies: costs, benefits, and issues. Admin Social Work 1992;16:11-23.

22 Walshe K, Walsh N. Evaluating accreditation programmes in healthcare. In: Walshe K, Walsh N, Schofield T, et al, eds. Accreditation in primary care: towards clinical governance. Oxford: Radcliffe Medical Press, 2000: 18-29.

23 Agency for Health Care Policy and Research (US Department of Health and Human Services). Using clinical practice guidelines to evaluate quality of care. AHCPR publication no. 95-0046. Rockville, MD: AHCPR, 1995

24 Lawrence M, Olesen F. Indicators of quality in health care. Eur J Gen Pract 1997;3:103-8.

25 Klazinga N. Re-engineering trust: the adoption and adaption of four models for external quality assurance of health save services in western European health care systems. Int J Qual Health Care 2000;12:183-9.

26 Coulter A. Why should health services be primary care-led? J Health Serv Res Policy 1996;1:122-4.

27 Wilkinson J, Murray S. Health needs assessment. Assessment in primary care: practical issues and possible approaches. BM 1998;316:1524-8.

28 Britt H, Miller G. Steven I, et al. Collecting data on potentially harmful events: a method for monitoring incidents in general practice. Fam Pract 1997:14:101-6.

29 Bhasale A, Miller G, Reid S, et al. Analysing potential harm in Australian general practice: an incident-monitoring study. Med J Aust $1998 ; 169: 73-6$

30 Wilson $T$, Sheikh A. Enhancing public safety in primary care. BM 2002;324:584-7.

31 Department of Commonwealth and Aged Care. An outline of the Practice Incentives Program. Adelaide, South Australia: Department of Commonwealth and Aged Care, 2001.

32 Scrivens E. Putting continuous quality improvement into accreditation: improving approaches to quality assessment. Qual Health Care 1997;6:212-8

33 Walshe K, Wallace L, Freeman T, et al. The external review of quality improvement in health care organizations: a qualitative study. Int J Qual Health Care 2001;13:367-74.

34 Young R, Leese B, Sibbald B. Imbalances in the GP labour market in the United Kingdom: evidence from a postal survey and interviews with GP leavers. Work, Employment Society 2001;15:699-715.
35 Campbell S, Sheaff R, Sibbald B, et al. Implementing clinical governance in English primary care groups/trusts: reconciling quality improvement and quality assurance. Qual Saf Health Care 2002:11:9-14.

36 Leatherman S, Sutherland K. Evolving quality in the new NHS: policy, process and pragmatic considerations. Qual Health Care 1998;7(Suppl):S54-61.

37 Bollen M. Accreditation: the key to your future. Qual Health Care 1996:5: 1523-5.

38 Castell A, Perry S. Quality improvement training manual. Seattle: Genetic Services Section of Washington State Department of Health, 1996: 1-102

39 Shortell S, Bennett C, Byck G. Assessing the impact of continuous quality improvement in clinical practice: what it will take to accelerate progress. Milbank Quarterly 1998;76:593-619.

40 Grol R. Improving the quality of medical care. Building bridges among professional pride, payer profit, and patient satisfaction. JAMA $2001 ; 286: 2578-85$

41 Grol R. Between evidence-based practice and total quality management: the implementation of cost-effective care. Int J Qual Health Care 2000;1 2:297-304.

42 Donabedian A. Quality assessment and assurance: unity of purpose, diversity of means. Inquiry 1988;25:173.

43 Donaldson L, Muir Gray J. Clinical governance: a quality duty for health organisations. Qual Health Care 1998;7(Suppl):S37-44.

44 Klein R. Can policy drive quality? Qual Health Care 1998;7(Suppl):S51-3.

45 Sheldon T. Promoting health care quality: what role performance indicators? Qual Health Care 1998;7(Suppl):S45-50.

46 Weissman H. Accreditation, credentialing and accountability. Admin Social Work 1980:4:41-52.

47 Buetow S, Roland M. Clinical governance: bridging the gap between managerial and clinical approaches to quality of care. Qual Health Care 1999;8: 184-90.

48 Graham J. Accreditation of general practices: a consumer perspective. In: Douglas R, Saltman D, eds. Everyone's watching: accreditation of general practice. NCEPH discussion paper no. 7. Canberra: NCEPH, 1992.

49 Martin C. Accreditation: a commentary. In: Douglas R, Saltman D, eds. Everyone's watching: accreditation of general practice. NCEPH discussion paper no. 7. Canberra: NCEPH, 1992.

50 Schyve PM. The evolution of external quality evaluation: observations from the Joint Commission on Accreditation of Healthcare Organizations. Int J Qual Health Care 2000;12:255-8.

51 Royal College of General Practitioners (RCGP). Quality team development - an accredited approach to quality improvement for primary health care teams. London: RCGP, 2002: 1-2.

52 Royal College of General Practitioners Scotland. Practice accreditation. 2002

53 Carter Y, Shaw S, Macfarlane F. Primary Care Research Team Assessment (PCRTA): development and evaluation. Royal College of General Practitioners Occasional Paper Series, No. 81. London: Royal College of General Practitioners, 2002

54 Ram P, Grol R, van den Hombergh P, et al. Structure and process: the relationship between practice management and actual clinical performance in general practice. Fam Pract 1998;15:354-62

55 Royal New Zealand College of General Practitioners (RNZCGP) Aiming for excellence. An assessment tool for general practice. Wellington: RNZCGP, 2002

56 AGPAL. AGPAL, general practice accreditation. Milton, Queensland: AGPAL, 2001.

57 Miller G, Stirton J, Smith D, et al. Field test of entry standards for general practice. Condensed report. Sydney: Royal Australian College of General Practitioners, 1995

58 Mara P, Vining R, Braithwaite J. Local demonstration trials of standards and accreditation for general practice. Canberra: Commonwealth Department of Human Services and Health, 1995.

59 Eliasson G, Berg L, Carlsson P, et al. Facilitating quality improvement in primary health care by practice visiting. Qual Saf Health Care 1998:7:48-54 